\title{
DEL OPERAISMO AL (POST)OPERAISMO: LA IMPORTANCIA DEL CRUCE CON EL POST-ESTRUCTURALISMO FRANCÉS
}

\author{
ANTONIO GÓMEZ VILLAR \\ Universitat de Barcelona \\ Universitat Autònoma de Barcelona
}

\begin{abstract}
RESUMEN: Este artículo tiene por objetivo poner en valor la importancia del post-estructuralismo francés en el tránsito del operaismo al (post)operaismo. El encuentro entre la corriente francesa e italiana no es tanto un proyecto para reunir ambos pensamientos, como un proceso de revelamiento de resonancias previas. Lo que abre la verdadera posibilidad de encuentro entre ambas corrientes son los lazos teóricos profundos que preexistían a la contingencia del encuentro. El resultado de ese encuentro no puede ser reducido a una unidad. Penetraremos en él desde las grietas y fisuras de sus formas desbordantes y disruptivas.
\end{abstract}

PALABRAS CLAVES: operaismo; pos-estructuralismo; Negri; Foucault; Deleuze.

\section{From Operaismo to (Post)Operaismo: The Importance of the Cross with French Post-Structuralism}

ABSTRACT: The aim of this article is to highlight the importance of French post-structuralism in the transition from operaismo to (post)operaismo [«workerism» to «post-workerism»]. The meeting between the French and Italian movements was not so much a project to unite the two schools of thought, but a process to reveal earlier resonances. What paved the way to a meeting between the movements were the deep theoretical ties that existed before the contingency of such a meeting. The outcome of that meeting cannot be reduced to a unit. This article explores it through the cracks and fissures of its sprawling, disruptive forms.

KEY WORDS: operaism; post-estructuralism; Negri; Foucault; Deleuze.

\section{INTRODUCCIÓN}

Este artículo tiene por objetivo desarrollar las dos intensidades que hemos identificado como claves en la transición deloperaismo al (post)operaismo. En primer lugar, el paso del «obrero masa» al «obrero social» que describe Toni Negri; y, el segundo punto de inflexión en esta transición a lo post-, el encuentro del operaismo italiano con el post-estructuralismo francés, las temáticas del deseo, la obra de Deleuze y Guattari y la genealogía foucaultiana del poder y de la subjetividad.

En el primer apartado, inscribiremos el operaismo y su lectura de la obra de Karl Marx en el marco de las distintas perspectivas y enfoques que tuvieron lugar durante la década de los años sesenta y setenta; en segundo lugar, señalaremos los principales locus de enunciación - revistas y organizaciones- a partir de los cuales, y a través del devenir político de las mismas, se articuló la teoría operaista. Sobre estos dos primeros elementos de análisis no nos detendremos en demasía, pues no es objeto 
de este artículo cartografiar, ni desde una perspectiva historiográfica, ni desde la historia de las ideas, los movimientos y organizaciones operaistas; sí prestaremos mayor atención a sus operaciones filosóficas, especialmente a los conceptos y las categorías que se derivan de lo que Mario Tronti llamó la "revolución copernicana» del operaismo italiano.

En los dos apartados siguientes, vamos a atender a las dos intensidades que hemos identificado en el transcurso de esta investigación como claves en la transición del operaismo al (post)operaismo, estas son, el tránsito del obrero masa al obrero social; y el encuentro con el post-estructuralismo francés. Cartografiaremos los principales lazos teóricos entre ambas corrientes que versan, sobre todo, en torno al rechazo de la consecuencialidad determinista entre la estructura del presente y la forma posible del futuro; la concepción del capital como relación social y no como cosa; la creencia en la autonomía singular como fuerza de enunciación, de creación y liberación; y el planteamiento del problema social como un problema de la autonomía y como posibilidad de una subjetivación autónoma.

\section{LA NARRATIVA OPERAISTA: LA «REVOLUCIÓN COPERNICANA», LA «COMPOSICIÓN DE CLASE» Y «LOS CICLOS DE LUCHA»}

Las diferentes lecturas que de la obra de Marx se hicieron durante la década de los años sesenta y setenta fueron abordadas principalmente desde tres perspectivas, cada una de las cuales estaba relaciona con cada una de las tres fases en las que ha sido dividido el trabajo teórico de Marx: el joven Marx de las Obras filosóficas juveniles de 1844, el Marx de El Capital, y el Marx de los Grundrisse.

La primera de las lecturas se centraba en la vocación humanista de Marx y en la cuestión de la subjetividad. Esta perspectiva humanista del pensamiento crítico revolucionario de los años sesenta es identificable a través de Hebert Marcuse y Jean Paul Sartre; la segunda corriente puso su atención sobre El Capital, o sea, en el Marx de las obras posteriores a la ruptura epistemológica señalada por Althusser, que se apartaba de las interpretaciones que no hacían justicia al carácter científico de los trabajos de Marx a partir de 1845; el tercer y último derrotero retoma los influjos conceptuales de la fenomenología, descubre la importancia de los Grundrisse y, a partir de ese texto, elabora el concepto de «composición de clase» y de general intellect.

Es en esta tercera directriz donde se sitúa el operaismo italiano. En efecto, desde finales de los años sesenta, la reflexión operaista prestó especial atención a los Grundrisse ${ }^{1}$, texto que había sido ignorado por la tradición comunista de la Tercera Internacional. Especialmente importante en la formación del marco conceptual operaista fue el «Fragmento sobre las máquinas», un texto recogido en el segundo volumen de los Grundrisse.

La lectura operaista coexistió contemporáneamente con otras lecturas marxistas, y se constituyó como alternativa teórica a ellas. En primer lugar, se desligó de la

1 MARX, K., Elementos fundamentales para la crítica de la economía política (Grundrisse). Madrid: Siglo XXI, 2007. 
ortodoxia marxista prevaleciente en los partidos comunistas, sobre todo a partir de la invasión soviética de Hungría en 1956; se apartó igualmente de la construcción subjetivista de E.P. Thompson, desarrollada en La formación de la clase obrera en Inglaterra, al considerar que ésta, tras la acumulación de hechos subjetivos, termina asumiendo la domesticación progresiva del proletariado; también fue una alternativa a la «Teoría Crítica» elaborada por los miembros de la «Escuela de Frankfurt»; fue una lectura diferenciada de la realizada por Sartre y la perspectiva del existencialismo humanista centrada en los valores humanistas de Marx; y, por último, marcó diferencias con el estructuralismo de Althusser — si bien el operaismo italiano produjo una ruptura teórica respecto a muchos elementos althusserianos, coincide en otros con la crítica al revisionismo formulada por el filósofo francés.

El operaismo fue un movimiento político y filosófico que apareció en Italia en los años sesenta, en un contexto de transformación cultural profunda. Nace con la revista Quaderni Rossi, fundada por Raniero Panzieri en 1959, cuyo primer número salió en 1961 a partir de la iniciativa de diversos grupos políticos radicados en varias ciudades industriales italianas. Quaderni Rossi representó el renacimiento del marxismo en Italia fuera del partido comunista, cuya producción teórica se conoció como operaismo. A partir del estudio de la fenomenología de la condición obrera, ahondaron en la nueva realidad del rechazo del trabajo que, sobre todo, en la gran fábrica turinesa de la FIAT de Mirafiori, se manifestaba en formas que desbordaban y excedían la gramática política de los partidos de izquierdas y sindicatos, inscritos en la lógica de la representación.

En este sentido, el origen y la constitución del operaismo radica en un grupo de intelectuales que se situaban al margen y eran periféricos a los grandes partidos de la izquierda italiana. Su principal propósito era lo que entonces se denominó inchiesta operaia [ "encuesta obrera»], que consistía en cartografiar en la fábrica la emergencia de las nuevas figuras obreras y especialmente sus aspectos subjetivos más subversivos, lo que se conoció como «rechazo del trabajo». La investigación se centró principalmente en la modificación de la composición de la clase obrera.

Entre los años 1963 y 1966, la evolución de la revista acabó en una escisión del grupo originario, marcada, de un lado, por el alejamiento en 1967 de quienes, como Mario Tronti o Asor Rosa, deciden entrar o continuar dentro del Partido Comunista italiano (PCI) con la intención de modificarlo desde dentro; y, por otro, quienes como Toni Negri, se plantean la participación en organizaciones obreras autónomas. De aquella escisión surgió la revista Classe Operaia dirigida por Mario Tronti, Sergio Bologna y Antonio Negri, con una vocación ya decidida de intervención política: «no solo se propone continuar la investigación teórica de los Quaderni Rossi, sino fortalecer también la acción política en el interior de las fábricas $»^{2}$. A pesar de la ruptura mencionada, ambas corrientes tratan de mantener un laboratorio de investigación común a través de la revista Contropiano, dirigida por Asor Rosa, Massimo Cacciari y Toni Negri.

Quienes son partidarios de las tesis de Toni Negri acerca de la participación en organizaciones autónomas, organizan el grupo de acción Potere Operaio, otra

2 TrontI, M., Obreros y capital, Oscar Chávez Hernández, David Gámez Hernández, Carlos Prieto del Campo, tr., Madrid: Akal, [1996] 2001. 
de las organizaciones fundamentales en el devenir del operaismo: fue la primera organización operaista con vocación de masas que se estructura a nivel estatal. De carácter neoleninista, su acción se orientaba, principalmente, hacia las fábricas, pero tenía también una importante influencia en las universidades. Surgió al calor de las movilizaciones de 1968 en Europa y Estados Unidos, y supuso la fusión entre movimientos estudiantiles y obreros. Aspiraban a poner en práctica los conceptos de «rechazo del trabajo» y autonomía de la clase obrera. El primer grupo se formó en Venecia en 1967; y en otoño de 1969 se constituyó como organización en toda Italia. En 1973, con el declive del primer ciclo de luchas del 68 italiano, Potere Operaio se disolvió para dar lugar a nuevos experimentos políticos. Entre estos nuevos experimentos, en 1973, Paolo Virno y otros miembros de Potere Operaio, fundaron una revista para pensar las formas de vida que se proyectaban más allá de la «época del trabajo». La revista se llamó Metrópoli, cuyos miembros, en 1979, en el marco de la operación represiva contra el movimiento italiano, son encarcelados en el llamado «juicio 7 de abril», también conocido como «el juicio de Toni Negri».

Estos fueron los principales lugares de producción y recepción del operaismo a través de las diferentes revistas y organizaciones. Sin embargo, en este artículo nos interesa detenernos en los conceptos que se derivan de la, así llamada por Mario Tronti, «revolución copernicana», en la medida en que funda el gesto filosófico que está en el origen del operaismo italiano.

En 1966, Mario Tronti publica Obreros y Capital, una obra que marca la ruptura teórica que inaugura el operaismo. Partiendo de una reelaboración filosófica de la relación entre el marxismo y Hegel, que por aquellos años era lugar común en cualquier posicionamiento teórico, Tronti expresó la llamada «revolución copernicana» con aquél "primero las luchas, luego el desarrollo capitalista». El primer número de la revista Classe Operaia, cuyos números siempre tenían una orientación monográfica, Lenin in Inghilterra, comenzaba con el famoso artículo homónimo de Tronti, en el que exponía con claridad el giro radical en el análisis teórico de la relación entre luchas obreras y desarrollo capitalista:

También nosotros hemos visto antes el desarrollo capitalista y, después, las luchas obreras. Es un error. Es preciso dar la vuelta al problema, cambiar el signo, volver a empezar desde el principio: y el principio es la lucha de clases obrera. Desde la perspectiva del capital socialmente desarrollado, el desarrollo capitalista está subordinado a las luchas obreras, viene después de éstas y hace corresponder a éstas el mecanismo político de su propia producción ${ }^{3}$.

Para Tronti, la resistencia siempre es anterior en relación al poder; las revueltas de la clase trabajadora anteceden y prefiguran los desarrollos posteriores del capital. En otras palabras, las revueltas constituyen una fuerza creativa que, incluso si no sale inmediatamente victoriosa, determinará los modos de desarrollo futuro del capital. Esta proposición hace hincapié en la potencia y en la creatividad de la lucha, reconoce la primacía constituyente de la clase obrera.

Los trabajadores no son, pues, un elemento pasivo de los designios capitalistas, «la víctima reactiva pasiva», sino los sujetos activos de la producción, la fuente de

3 Trontr, M., Obreros y capital, Oscar Chávez Hernández, David Gámez Hernández, Carlos Prieto del Campo, tr., Madrid: Akal, [1996] 2001, 93. 
innovación de la cual depende el capital. La clase obrera no es solo el sujeto de la explotación, sino también el sujeto de poder; no es solo el sujeto pasivo construido mediante los dispositivos de la dominación capitalistas, sino el sujeto activo que se constituye a sí mismo.

Este planteamiento comporta una ruptura teórica que invierte la relación entre la dinámica tecno-productiva del capital y el movimiento subjetivo de clase. Es la evolución de las modalidades que adoptan las formas de organización y sabotaje que la subjetividad obrera expresa las que influyen y modifican la organización estructural de la producción y las formas técnicas en las que se determina el capital, y no al revés. En términos de $\mathrm{Bifo}^{4}$, «la autonomía obrera obliga al capital a redefinir sus estructuras técnicas y sus equilibrios institucionales ${ }^{5}$.

En la tradición marxista, el concepto de clase obrera fue construido de manera estática, como figura interna al capital que imposibilitaba convertir el movimiento de clase en una variable independiente de la relación de capital. Para el operaismo, por el contrario, la clase obrera se definía por su ser subjetivo frente a las interpretaciones objetivistas y estructuralistas. La perspectiva que inaugura el operaismo consistió en pasar del estudio de las leyes del movimiento de la sociedad capitalista al análisis de las leyes del movimiento del trabajo y de la resistencia obrera.

En relación a la «revolución copernicana» que acabamos de describir, el operaismo acuña el concepto de "composición de clase ${ }^{6}$, el cual comporta, al menos, dos operaciones filosóficas importantes. En primer lugar, el concepto «composición de clase» fue introducido, en cierto sentido, contra los planteamientos idealistas desde la perspectiva de la conciencia de clase. Si la «composición de clase» tenía como objeto reemplazar la idea de "conciencia», ello supuso la impugnación de la relación que en el marxismo clásico se abría entre la conciencia de clase y el Partido como sujeto separado. La conciencia era justamente lo que unía la materialidad de la clase obrera y su expansión política. Y esta conciencia venía de fuera, del Partido. La conciencia de clase, así, permitía «alcanzar lo universal desde el autoconocimiento concreto de la explotación ${ }^{7}$.

Se produce, entonces, una importante ruptura en el pensamiento marxista de lo político: pues lo político ya no es algo que pueda ser aprehendido de forma separada de los procesos de lucha en tanto que no pertenece al ámbito de la conciencia, sino que se desarrolla en estos mismos procesos. El devenir de la subjetividad

4 A Franco Berardi se le conoce como «Bifo» desde que en la adolescencia firmara con ese pseudónimo sus pinturas abstractas

5 Berardi, F. (Bifo), La sublevación. Barcelona: Artefakte, [2011] 2013, 34.

6 Franco Berardi (Bifo) define en varios de sus escritos al operaismo como "composicionismo», un pensamiento composicionista. De hecho, el término operaista le parece reduccionista "El "composicionismo" nos permite imaginar la dinámica social como un proceso fluido en el cual se mezclan químicamente flujos culturales, flujos químicos y flujos ideológicos, toda la materia que escapa a las categorías pétreas de la política". Véase BERARDI, Franco (Bifo). Il sapiente, il mercante, il guerriero. Dal rifiuto del lavoro all'emergere del cognitariato. Roma: DeriveApprodi, 2004.

7 López Petiт, S., «La precariedad como forma de humillación. Algunas reflexiones muy provisionales sobre la precariedad». En Delgado, M. (ed.), La humillación. Técnicas y discursos para la exclusión social. Barcelona: Bellaterra, 2009. 
obrera no va a ser descrito en términos ideológicos ni organizativos, como en la Tercera Internacional, sino como «composición de clase». No hay lugar para la transformación de la conciencia espontánea en conciencia revolucionaria.

Por «composición de clase» entenderá el operaismo, entonces, un conjunto de datos, objetivos y subjetivos, que caracterizan a una clase trabajadora en particular, definida por la forma y los contenidos de los procesos de trabajo; por las necesidades obreras históricamente consolidadas; y por las diferentes experiencias subjetivas. Tres son los elementos fundamentales que subyacen a la teoría de la "composición de clase»: la existencia de conflictos permanentes protagonizados por los obreros contra la organización capitalista de la producción; la constatación de que el capital siempre se constituye como respuesta a las luchas de los trabajadores; y el convencimiento de que después de cada ciclo de lucha existen residuos políticos encarnados en la estructura subjetiva de la fuerza de trabajo. La intuición política fundamental del operaismo es la siguiente: la evolución humana es un proceso de autonomización del tiempo de vida respecto del tiempo de trabajo.

La segunda de las operaciones filosóficas que se derivan del concepto «composición de clase» tiene que ver con el desmontaje de la noción de sujeto que el marxismo había heredado de la tradición hegeliana. El operaismo deja de pensar desde el sujeto histórico: «el concepto de clase obrera no tiene una consistencia ontológica, sino que ha de ser entendido como un concepto vectorial ${ }^{8}$. Dicho en otros términos, no es el capital el que otorga un estatuto ontológico de clase a los trabajadores, sino que son sus luchas las que los constituyen como clase, ésta no existe con anterioridad a las luchas. El operaismo desarrolló una lectura de la clase como sujeto que se constituye en la lucha. No es, pues, la conciencia empírica de los obreros y el proceder gradual de la organización subjetiva, entendida sociológicamente, la que determina el proceso de reestructuración capitalista y las respuestas políticas y tecnológicas del capital, sino la composición de clase tomada en su conjunto.

Esta segunda operación filosófica implica, a su vez, el abandono del historicismo dialéctico que dominó el panorama filosófico del movimiento obrero en el siglo $\mathrm{XX}$, que había fundado un método cognoscitivo y estratégico de tipo dialéctico. El operaismo se sustrajo al historicismo dialéctico porque no pensaba en términos de transición histórica, ni en términos de superación del capitalismo y de realización de una esfera totalizante comunista. Pensaba, por el contrario, en términos de autonomía. El operaismo abandona la dialéctica y asume el antagonismo.

La «revolución copernicana» puso en cuestión el método historicista del marxismo. El historicismo hacía corresponder distintos estadios de conciencia y de organización política a distintos estadios de desarrollo de las fuerzas productivas. Tronti, por el contrario, sostiene: solo partiendo de la historia interna de la clase obrera es posible comprender el esfuerzo de reorganización económica y política que el capital debe realizar continuamente.

Y es que para el operaismo la clase obrera tiene su propia lógica: una lógica no dialéctica sino de antagonismo, de separación; no busca controlar a su opuesto

8 Berardi, F. (Bifo), Generación post-alfa. Patologías e imaginarios en el semiocapitalismo, Patricia Amigot, Manuel Aguilar, Diego Picotto, tr. Buenos Aires: Tinta Limón, 2007, 85. 
—esa es, precisamente, la lógica dialéctica con la que funciona el capital- sino destruirlo y alcanzar su liberación. El método dialéctico es el modo de existencia del capital, pues, en cada disputa con el trabajo, toda lucha de éste es recuperada desde la lógica de aquél.

La «revolución copernicana» es también un gesto ontológico: la lucha no es entre un sujeto —el capital—y el objeto de su explotación —el proletariado; sino entre un sujeto y un sujeto: «la subordinación de la fuerza de trabajo al capital es revertida, se presenta como potencia política. La fuerza de trabajo es conceptualizada como el verdadero sujeto, técnico y político, de la producción ${ }^{9}$. Ya no es más un margen, un residuo, un desecho. Es un sujeto que expresa potencia. Es Toni Negri quien con mayor profundidad ha reemplazado la negación dialéctica por una negación no dialéctica pensada desde Baruch Spinoza. En su obra La anomalía salvaje. Ensayo sobre poder y potencia en B. Spinoza, publicado en 1981 y escrito en prisión, intentó construir una lectura diferente de la filosofía spinoziana:

El problema que suscita Spinoza es el de la posibilidad, en el corazón de la modernidad, de un pensamiento democrático, de una hipótesis de gobierno de la multitud, de una institucionalización de lo común. Es el problema de la posibilidad de que estos elementos puedan darse en la inmanencia, a contramano de toda afirmación de trascendencia soberana ${ }^{10}$.

En Spinoza solo hay potencia, es decir, libertad que se opone a la nada y construye lo común. Spinoza ni siquiera toma en consideración la dialéctica, se coloca radicalmente fuera de ella. Negri observa en el pensamiento de Spinoza una base de anticipada crítica a la dialéctica hegeliana y de fundación del método materialista. Spinoza como anomalía salvaje.

El segundo concepto operaista fundamental que se deriva de la «revolución copernicana» es el de «ciclo de lucha», introducido como alternativa teórica a los análisis realizados en clave de acumulación lineal. Cuando los trabajadores, desde el antagonismo, a través de los intentos de escapar al dominio y control del capital, se movilizan y alcanzan algún grado de unidad, o sea, algún grado de composición de clase, el capital responde con una reordenación de su poder de mando mediante innovaciones organizacionales, políticas y tecnológicas, con el objeto de descomponer estos movimientos. Si el capital busca descomponer la composición de clase a través de fuertes reestructuraciones y cambios organizacionales, la composición de clase se encuentra, entonces, en permanente cambio, innovando procesos de resistencia y ataque. A su vez, cada reestructuración capitalista, provoca una nueva recomposición de clase con renovadas capacidades de resistencia. Así, cada ciclo de lucha contiene tres momentos: composición, descomposición y recomposición.

Este triple proceso que contiene cada ciclo de lucha supone que la fuerza de trabajo es introducida en la relación capital/trabajo no solo como mercancía, como objeto; sino sobre todo como fuerza política, es decir, como clase antagonista. Vemos, pues, que el proletariado adopta un doble carácter simultáneo: de un

9 Negri, A., Kairos, Alma, Venus, Mutitudo. Roma: Manifestolibri, 2000, 56.

10 Negri, A., La anlomalía salvaje. Ensayo sobre poder y potencia en Baruch Spinoza. Barcelona: Anthropos, 1993, 24-25. 
lado, como agente negador a través de sus intentos de fuga del poder de mando; de otro, como agente creador del capital, en tanto que son las luchas obreras las que empujan y obligan al capital a innovar para renovar su poder de dominio y control. Este doble carácter que se da de forma simultánea es precisamente lo que define al capital como crisis. La crisis se formula a partir de la tríada: lucha obrera (composición) - crisis (descomposición) - reestructuración (recomposición).

Resumiendo, la «revolución copernicana», la «composición de clase» y los «ciclos de lucha» forman parte de una misma narrativa: una composición técnica implica una cierta composición política que conduce a un nuevo ciclo de luchas; ello obliga al capital a transformar su poder de mando, que a su vez dará lugar a una nueva composición de clase, comenzando el ciclo de nuevo. A ciertas formas adoptadas por la organización de la producción -composición técnica- deben corresponder ciertos patrones de comportamiento político que prefiguran las respuestas inmanentes a aquellas formas - composición política-, la intensificación e interconexión de las cuales pueden generar un nuevo ciclo de luchas.

2. El (POST) OPERAISMO: REDEFINIENDO EL CAMPO CONCEPTUAL DE CLASE Y DE LA AUTONOMÍA. DEL «OBRERO MASA» AL «OBRERO SOCIAL»

La periodización del desarrollo capitalista que desarrolla el operaismo italiano, del «obrero masa» al «obrero social», se corresponde en paralelo a la periodización que marca la transición del operaismo al (post)operaismo. El «obrero masa» es conceptualizado como el obrero de la gran industria, siendo la fábrica el lugar privilegiado como espacio de las principales luchas. Se caracteriza por ser un trabajador que se convierte en prótesis de la máquina, en oposición a la figura del obrero profesional, del trabajador artesanal independiente, que se corresponde con la época de la manufactura: «desde la perspectiva de los procesos de trabajo, el obrero masa es una figura obrera que, por primera vez de manera global, es introducido dentro de lo que Negri llama el "mando de la maquinaria" ${ }^{11}$.

Siguiendo con la periodización conceptualizada por el operaismo, los años setenta suponen el fin de la figura del "obrero masa", tanto en términos de organización capitalista del trabajo como en términos de su hegemonía política y cultural. La figura que emerge en el tránsito de la sociedad fordista a la fábricasocial es el «obrero social». La conceptualización de esta figura constituyó el aporte sustantivo de Toni Negri en aquella época ${ }^{12}$. Si el obrero masa correspondía a una fase marcada por una concepción de la centralidad de la fábrica como espacio de luchas, con el obrero social las luchas se extienden al conjunto de la sociedad. Es la época de la consigna Take over the city [«sitiemos la ciudad»], que acuñó el grupo Lotta Continua.

11 RevelLi, M., Más allá del siglo XX. La política, las ideologías y las asechanzas del trabajo, María del Mar Portillo y Marco Barberi, tr., Barcelona: El Viejo Topo, 2002, 145.

12 Negri, A., Dall'operaio massa all'operaio sociale: intervista sull'operaismo (a cura di Paolo Pozzi e Roberta Tommasini). Milano: Multhipla, 1979. 
El proceso de recomposición de clase del «obrero masa» había sido analizado dentro de la esfera del trabajo industrial; el proceso de recomposición del obrero social, en cambio, va a afectar no ya al conjunto de la sociedad, la fábrica-social, sino que se extiende a todas las actividades genéricamente humanas: el lenguaje como la forma general del trabajo productivo postfordista. El trabajo material inmediatamente productivo pierde su papel central en el proceso de producción, mientras emerge esta nueva figura del «obrero social», que se presenta como el intérprete de las funciones de cooperación laboral impulsadas por las redes productivas sociales.

Esta ampliación del campo del análisis, que marca el tránsito del «obrero masa» al «obrero social», es, quizás, la intuición política fundamental que señala el comienzo del (post)operaismo, que contribuye a redefinir el campo conceptual de recomposición de clase y de la autonomía; un tránsito que ha producido nuevas subjetividades y ha definido nuevas relaciones culturales y políticas. El desarrollo del (post)operaismo como tendencia continuadora del operaismo está ligado, pues, a la conceptualización de la figura del «obrero social».

Esta decisiva transición estuvo circunscrita, en un primer momento, al ámbito italiano; y, más tarde, ramificado a nivel internacional. Sandro Mezzadra, en su texto En la época de los post, sostiene que el anteponer post- al operaismo no fue obra de ninguno de los teóricos que se asocian a esta etiqueta, sino que ésta se formó en el mundo anglosajón: «seguramente fue allí donde, en la intersección entre la academia global, el activismo "altermundista" y los mundos artísticos, llegó a ser de uso común para volver luego a Italia, a Francia, a Brasil y a otros países donde tiene lugar la elaboración (en la actualidad totalmente transnacional) de las teorías que a partir de un determinado momento se han definido como (post) operaistas ${ }^{13}$.

De hecho, Italian Theory es un nombre acuñado por la academia angloparlante, al igual que sucedió antes con el término de French Theory. Se considera el libro editado por Paolo Virno y Michael Hardt, Radical Thought in Italy, en 1996, como la irrupción oficial del (post)operaismo italiano en el mundo académico norteamericano. Sobre este nexo entre la Italian y la French Theory sostiene Negri que «el operaismo expande el proyecto de una ontología constitutiva que comienza donde el pensamiento francés había dejado las máquinas deseantes y la micropolítica» ${ }^{14}$.

En el apartado anterior proponíamos un recorrido de los principales agenciamientos colectivos de enunciación operaistas. Ahora haremos lo propio con el (post)operaismo, atendiendo, claro está, a la ramificación internacional que señala Mezzadra. La internacionalización del (post)operaismo comporta también la apertura, el contacto y la permeabilidad con marcos teóricos diversos; así como

13 Sandro, M., «En la época de lo post». En Marazzi, C., Berardi, F. (Bifo), y Mezzadra, S., Balance conceptual del post-operaismo en Italia. Espai en Blanc: El impasse de lo político, núm. 9, pp. 293-297, 2011.

14 Pasquinelli, M. (2013). «La potenza di astrazione e il suo antagonismo. Sulle psicopatologie del capitalismo cognitivo", UniNomade 2.0, 28, marzo, 2013 [http://www. uninomade.org/la-potenza-di-astrazione-e-il-suo-antagonismo/] [Consultado: 31 de marzo de 2013]. 
transformaciones de sus planteamientos teóricos y metodológicos, que en buena medida se deben al desafío que plantea la recepción de la teoría (post)operaista en contextos sociales, políticos y culturales que difieren, y mucho, del italiano.

Entre noviembre de 1990 y junio de 1993, se produce un nuevo inicio de la actividad política —después de los encarcelamientos, represión y exilio que sufrieron muchos de los miembros de la autonomía italiana- a través de la revista Luogo Comune, de la cual se publicaron cuatro números. Este nuevo florecimiento de producción teórica está marcado por la transición entre el operaismo y el (post) operaismo. En el proyecto de Luogo Comune colaboraban Paolo Virno, Giorgio Agamben, Franco Piperno, Antonio Negri, Sandro Mezzadra y Sergio Bianchi. La revista se centraba en el análisis de las figuras del trabajo social. Más tarde, Luogo Comune puso el centro de su atención en el «Fragmento sobre las máquinas» de los Grundrisse de Marx y, sobre todo, en el concepto de general intellect. Hija de Luogo Comune es DeriveApprodi, fundada en 1992. Con esta última, se presentó el problema de cómo traducir y transformar los discursos sobre el general intellect, la multitud o el éxodo en formas concretas de lucha. Derive Approdi y su labor editorial están a la base de la renovación de los movimientos políticos sociales en Italia.

Otra revista y proyecto intelectual fundamental en la reactualización teórica del operaismo y en la proposición teórica de una nueva batería de conceptos de indudable valor para los movimientos sociales ha sido Futur Antérieur, fundada entre otros por Toni Negri durante su exilio en Francia. La revista comenzó a publicarse a principios de los años noventa y reunió a un espectro amplio de la izquierda francesa. A Futur Antérieur le sucedió la revista Multitudes, fundada por Antonio Negri y Jean-Marie Vincent, y desde su comienzo participó de forma activa en los foros sociales mundiales y en el movimiento antiglobalización.

Actualmente, las revistas DeriveApprodi y Multitudes continúan siendo espacios de producción teórica (post)operaistas. Junto a ellas, hemos de hacer referencia también a las diferentes universidades nómadas de Italia (UniNomade), Brasil (Universidade Nômade) y España (Universidad Nómada), concebidas como dispositivos híbridos de intervención política transnacional a partir de las nuevas realidades de la composición de clase inmersa en el paradigma del general intellect. Dentro de UniNomade, en Italia, en 2012 se puso en marcha el proyecto Commonware, entendido como un laboratorio de producción teórica dentro y contra la Universidad, intentado poner luz a nuevas formas de organizar redes independientes de producción de conocimiento y la formación de instituciones autónomas del general intellect.

En España, otros tres proyectos se han erigido, en las últimas décadas, como receptores de la teoría (post)operaista, si bien abiertos a otros marcos teóricos y metodologías. En 1995 se puso en marcha Traficantes de Sueños, un proyecto de producción y comunicación política que aspiraba a aportar contenidos y animar debates útiles para la acción colectiva transformadora. La editorial ha traducido al castellano buena parte de la producción teórica (post)operaista, al igual que la colección «Cuestiones de antagonismo» de la editorial Akal. Más recientemente, en 2012, se constituyó la Fundación de los Comunes, una organización cuyo envite es constituirse en herramienta de transformación social, continuadora del proyecto Universidad Nómada. Y también de reciente creación, en Barcelona, la editorial 
Artefakte, a partir de la cual se está articulando un proyecto de organización autónoma de las capacidades cognitivas del precariado, generando una escisión constituyente al mando universitario.

También desde principios del siglo XXI, el Colectivo Situaciones en Argentina, organizado no tanto como un actor político orientador de las luchas y la estrategia, sino desarrollado a partir la figura del militante investigador, ha sido un lugar de recepción de la teoría y praxis (post)operaista. Un colectivo que trataba de organizarse a partir de una búsqueda de los procesos de producción material de valores capaces de transformar de raíz y desde abajo la sociabilidad actual. Desde el Colectivo Situaciones, la editorial Tinta Limón también ha dado a conocer numerosas obras en clave (post)operaistas. Actualmente, también en Argentina, existen tres espacios de elaboración, junto a otros marcos teóricos, de teoría (post)operaista: el blog Lobo suelto! (http://anarquiacoronada.blogspot.com.es/); el programa de radio Clinamen (http://ciudadclinamen.blogspot.com.es/); y el Instituto de Investigación y Experimentación política, cuyo objetivo central es producir momentos de comprensión e intervención en torno a una nueva conflictividad social en los territorios.

En resumen, el (post)operaismo es una corriente de pensamiento continuadora del operaismo, ¿Cuáles son los elementos que nos permiten hablar de la existencia de una corriente de pensamiento que posea una identidad mínima compartida? Hemos identificado varios. En primer lugar, los autores denominados (post) operaistas comparten aquello que Mario Tronti llamó la «revolución copernicana»: la subjetividad como punto de partida, la anterioridad de lo subjetivo respecto de la estructura. Los autores (post)operaistas se adhieren al presupuesto de que es en la capacidad de innovación y de cooperación del trabajo vivo donde residen los fundamentos de las formas históricas del capitalismo; rechazan tomar como núcleo de investigación el curso objetivo del capitalismo o las potencias simétricas y contrarias al capital.

Y, en relación a ello, un segundo elemento que une a los miembros de la corriente (post)operaista lo constituye el hecho de que no caen en descripciones sociológicas generales sobre la naturaleza del nuevo modo de producción, sino que operan desde el interior de las luchas y la producción de subjetividad. Proponen lecturas políticamente operativas, adoptando el pensamiento una función afirmativa y creadora. Ya el conocido como "Laboratorio Italia» de los años '60 y '70 fue un taller de experimentación, elaboración y práctica teórica en el interior de las luchas, desde la fenomenología de los comportamientos subversivos que expresaba el antagonismo obrero. Comenzaron a pensar la realidad subjetiva de los trabajadores inmateriales y a proponer una geografía variable de la nueva composición del trabajo como referentes de un análisis materialista y del proyecto antagonista. Además, supieron reconocer las posibilidades políticas que contenían las transformaciones atendiendo a las mutaciones de la subjetividad. Es en este sentido que destacamos que el (post)operaismo no nos ofrece descripciones sociológicas generales sobre la transición actual, sino elementos con los que operar desde el interior de las luchas y la producción de subjetividad. Los conceptos siempre son pensados desde la creación e invención de nuevas formas de autonomía y antagonismo, que dan cuenta de una topología de la resistencia del trabajo vivo. Sus análisis siempre tienen como punto de partida los bloqueos, los puntos de crisis, las rupturas, la 
apertura de nuevos planos y las líneas de fuga inmanentes a la nueva configuración del trabajo postfordista. Desde esta perspectiva, la pérdida de centralidad de la fábrica —elemento fundamental en los análisis (post)operaistas - es más política que sociológica, en tanto su configuración material actual es, al mismo tiempo, el resultado de procesos de lucha y la apertura de un nuevo campo de batalla. Así, al tiempo que se señala la extensión de los procesos de valorización al conjunto de la sociedad, se propone la transformación del lugar de la resistencia — de la fábrica a la metrópoli.

En lo que concierne a la metodología adoptada por el (post)operaismo en sus análisis, podemos hacer extensivo el carácter que Bifo atribuye a sus escritos como la metodología propia del (post)operaismo. Bifo sostiene que sus libros tienen un carácter rapsódico y no orgánico: recoge intuiciones y preocupaciones surgidas en épocas distintas y las desarrolla según campos diversos: categorías propias de la filosofía política, la ética, la epistemología, la economía política o la filosofía del lenguaje. Esta interdisciplinariedad se justifica en tanto los autores (post)operaistas siempre persiguen una amplitud de miras y perspectivas desde la que abordar los diferentes análisis. Este carácter rapsódico es también un rasgo fundamental del método recombinante frente a los desarrollos lineales, los análisis son fruto de una maduración en contextos bien diversos: situaciones de movilización, de discusiones y de luchas dentro y fuera de la academia, en diversos agenciamientos colectivos de enunciación que siempre acompañan el devenir de los movimientos sociales. En la vasta y extensa producción teórica (post)operaista se tratan temas que vuelven una y otra vez, mirados desde prismas y perspectivas distintas, y a la luz de objetos que desafían las categorías que ya venían siendo pensadas.

Desde el punto de vista de los elementos teóricos, la corriente (post)operaista está marcada por una fuerte heterogeneidad y diversidad. Pero podemos decir que comparten un elemento común fundamental: la atención por «lo económico». Con ello queremos decir que el (post)operaismo entiende que las transformaciones del capitalismo afectan a la vida y la subjetividad, que la política no es una esfera independiente de la economía. Para el (post)operaismo, la fuerza del capitalismo reside en su capacidad de articular la economía con la producción de subjetividad en diferentes aspectos. Desde esta perspectiva, si la subjetivación quiere existir y cobrar consistencia, entonces debe efectuar una ruptura, atravesando y reconfigurando lo económico, lo social y lo político.

El (post)operaismo es una corriente de pensamiento, insistimos, heterogénea, territorialmente dispersa y organizativamente fluida. Los análisis teóricos y compromisos de sus miembros con la acción siempre han estado atravesados por un alto grado de variación. Desde el punto de vista de los elementos teóricos, queremos señalar tres líneas de pensamiento diferenciadas al interior de la corriente: una primera sería la línea autonomista de corte más clásico, representado por Hardt y Negri, que combinan la teoría spinozista de la multitud y algunos temas postestructuralistas, con su fidelidad a gran parte de sus fuentes marxianas y operaistas - a través de conceptos tales como antagonismo, composición de clase, trabajo vivo o subsunción real; una segunda línea naturalista, dirigida por Paolo Virno, en torno a la multitud como forma de vida y a la teoría del postfordismo sobre las capacidades genéricas humanas — potencialidades - anclada en una filosofía del lenguaje y en una antropología post-heideggeriana; y una tercera corriente, que 
podríamos denominar de la diferencia y la ontología vitalista y del acontecimiento, representada por Maurizio Lazzarato y Franco Berardi (Bifo), que se alejan de las coordenadas clásicas del marxismo operaista y de la ontología del hacer negriana.

\section{3. (POST) OPERAISMO Y POST-ESTRUCTURALISMO: EL REVELAMIENTO DE UNA RELACIÓN SIMBIÓTICA}

A partir de 1977, los pensadores de la autonomía italiana entran en contacto con el post-estructuralismo francés a través de Foucault, Deleuze y Guattari. El exilio que emprendieron muchos de sus miembros a finales de los años setenta a París es sin duda un hecho biográfico fundamental que posibilita el contacto entre ambas corrientes. El momento clave fue septiembre de 1977, en Bolonia:

Había tanques en la ciudad... algunos intelectuales franceses vinieron a Italia, estaban Deleuze, Foucault, toda la izquierda intelectual que se oponía a la represión [...] con la entrada de los tanques en pleno centro de Bolonia para rodear el barrio de la Universidad, y con varias muertes entre los manifestantes en Bolonia y en Roma. Un grupo de intelectuales franceses organiza un coloquio sobre la represión en Bolonia, en septiembre. Foucault, Deleuze y Guattari toman posición a favor del «laboratorio político» italiano y denuncian vehementemente la violencia del Estado ${ }^{15}$.

A pesar de que las contingencias biográficas, marcadas por la fuerte represión sobre muchos de los miembros del operaismo italiano, que estando claramente a la base del encuentro entre ambas corrientes de pensamiento, consideramos que el encuentro no ha sido una mera casualidad motivada por acontecimientos políticos o biográficos. Antes bien, lo que abre la verdadera posibilidad de encuentro entre ambas corrientes son los lazos teóricos profundos que preexistían a la contingencia del encuentro. En este sentido, el cruce entre el (post)operaismo italiano y el postestructuralismo francés es tanto un proyecto para reunir ambos pensamientos, como un proceso de revelamiento de resonancias. Desde esta perspectiva, podríamos hablar de una relación simbiótica entre la experiencia italiana y francesa. Si bien es cierto que la recepción solo se ha dado, fundamentalmente, en un sentido: del pensamiento francés al italiano, un único flujo.

Ya antes del encuentro entre ambas corrientes, el operaismo había roto con la idea de una totalidad cerrada, portadora de una lógica rectora, e inscribió sus análisis en la heterogeneidad constitutiva de lo social. Este planteamiento es, justamente, el punto de partida de los análisis biopolíticos, la heterogeneidad de lo social: «a partir de los años setenta, las temáticas del deseo, la obra de Deleuze y Guattari, y la genealogía foucaultiana del poder y de la subjetividad, se revelan como el contexto filosófico más adecuado para encajar la reflexión (post)operaista sobre la producción de subjetividad y la transformación de los regímenes de trabajo ${ }^{16}$. La misma idea de capitalismo cognitivo, por ejemplo, propuesta por el

15 Negri, A., Job, la force de l'esclave. Paris: Bayard, 2002, 78.

16 Berardi, F. (Bifo), Il sapiente, il mercante, il guerriero. Dal rifiuto del lavoro all'emergere del cognitariato. Roma: DeriveApprodi, 2004, 231. 
grupo de pensadores ligados a Toni Negri y a la revista francesa Multitudes a partir de los años noventa, son herederas de la idea que atraviesa toda la obra de Deleuze y Guattari sobre sus análisis de la subjetividad en el capitalismo contemporáneo. Tiene lugar, pues, en ese momento, una correspondencia entre la filosofía francesa y aquello que acontecía en Italia desde un punto de vista político. Es por ello que nos parece del todo oportuna la reflexión de Michael Hardt, quien ha escrito que mientras la Francia del siglo XIX hizo política y Alemania hizo metafísica; en el siglo XX, Francia hizo metafísica e Italia política ${ }^{17}$.

Sobre los modos en los que discurre la relación entre las dos corrientes, Negri considera esencial subrayar que su relación con Deleuze y Guattari nunca fue de filiación, sino más bien de encuentro, «un puro y simple encuentro». Y esta relación que Negri describe, nosotros entendemos que es extensible al conjunto de los teóricos que podemos llamar (post)operaistas. Si se confundiese este encuentro con la relación de filiación, nunca se llegaría a entender, por ejemplo, en qué medida el (post)operaismo y el post-estructuralismo utilizan con frecuencia los mismos términos en sentidos muy diferentes: «sinceramente, no creo que haya peor tipo de relación que la filiación. ¡La familia tiene que ser destruida!» ${ }^{18}$.

En lo referente a la relación de ambas tradiciones con el pensamiento marxiano, hemos de apuntar que aunque las fuentes del pensamiento post-estructuralista y las del (post)operaismo son radicalmente distintas - las fuentes francesas eran Spinoza, Henri Bergson, Sigmund Freud, etc.; y el operaismo comenzó con Marx-, Deleuze y Guattari también articularon su pensamiento dentro de un dominio marxista. Más en concreto, desarrollaron sus conceptos en el contexto de una problemática marxista — de hecho, Deleuze nunca se enfrentó directamente con el marxismo, sino más bien con el estructuralismo-- a pesar de que ese dominio de pensamiento y esa problemática no era ni primordial ni consustancial a la formación intelectual de ambos.

El encuentro de la corriente (post)operaista con la lectura marxiana en clave post-estructuralista tuvo como resultado la transformación de la corriente de pensamiento italiana en, lo que podríamos llamar, un pensamiento comunista de la diferencia. En relación a ello, Negri sostiene que ni él ni Guattari abandonaron nunca el marxismo ${ }^{19}$, porque no creían en una filosofía política que no estuviese centrada en el análisis del capitalismo como sistema inmanente que no cesa de repeler sus propios límites y que se los vuelve a encontrar en una escala ampliada, porque el límite siempre es el propio capital:

Foucault, y con él Deleuze y Guattari, nos pusieron en guardia contra esta deriva. Eran revolucionarios. Cuando criticaban el estalinismo y las prácticas del «socialismo real» no lo hacían como hipócritas y fariseos, como «nuevos filósofos» del liberalismo, sino afirmando que sería posible expresar una nueva "potencia» del proletariado contra el «biopoder» capitalista. La resistencia al biopoder y la

17 Hardt, M., y Virno, P., (eds.). Radical Thought in Italy: A Potential Politics. Minneapolis: University of Minnesota Press, 1996, 8.

18 Casarino, C., y Negri, A., Elogio de lo común. Barcelona: Paidós, 2001, 147.

19 Negri, A., «Entrevista de Gilles Deleuze con Toni Negri», Magazín Dominical, núm. $511,1993,14-18$. 
construcción de nuevos estilos de vida no aparecerían, pues, alejadas de la figura de la militancia comunista ${ }^{20}$.

Otro aspecto importante que nos permite alumbrar el encuentro entre ambas corrientes es su oposición general al pensamiento hegeliano: «encontrar el pensamiento de Deleuze y Guattari, adquirir su modo de operar los conceptos y las palabras, ha significado para mí emprender una larga marcha de liberación de Hegel» ${ }^{21}$. La oposición al pensamiento hegeliano está a la base del rechazo de ambas corrientes a un fundamento trascendental, planteando, por el contrario, un fundamento inmanente; así como un rechazo a un fundamento teleológico determinado, alumbrando, en cambio, un fundamento material y abierto. Frente a Hegel, desarrollan una concepción no dialéctica de la negación.

En este sentido, la liquidación de toda concepción trascendental, la crítica de la causalidad determinista y la desmitificación de la teleología histórica que opera el (post)operaismo, abre un espacio de problematización que lo acerca al postestructuralismo. En efecto, el problema consiste en cómo restaurar la subjetividad, cómo colocarla en un plano de inmanencia, sin fines externos a sí misma, y reinterpretar la dimensión biopolítica como terreno de los dispositivos constituidos, o sea, el campo de inmanencia como campo biopolítico: no hay más un afuera, lo que está encerrado es el afuera. Esta reflexión está a la base de la teorización (post) operaista acerca de la sociedad-fábrica. El capital se ha convertido en una fábrica social, ha extendido los procesos de valorización al conjunto de la sociedad. La «subsunción real» no solo implica que los trabajadores se han convertido en parte de la máquina —o son, en sí mismos, la máquina—, sino que toda la sociedad es subordinada al movimiento expansivo e ilimitado del capital. La teoría de la fábrica integrada presupone, filosóficamente, la idea de una estructura productiva «monística». Pero si Deleuze y Guattari sacaron la máquina de la fábrica, en el postfordismo la fábrica ha salido de la fábrica, el conjunto de la sociedad se ha convertido en una fábrica. La fábrica fordista es hoy una fábrica sin paredes ni muros, se ha diseminado en la sociedad, desterritorializando, dispersando y descentralizando las operaciones, para construir lo que el (post)operaismo ha llamado la «fábrica-social», una fábrica difusa:

La tautología de la realidad [...] implica la existencia de una circularidad única de la que participan tanto la vida como la producción. [...] La producción capitalista es completamente autorreferencial, es decir, producción por la producción. La circularidad de la vida y de la producción capitalista se ha trabado. Eso, en definitiva, significa tautología de la realidad. La identificación entre capitalismo y realidad tiene como efecto convertir la vida en la auténtica forma de dominio ${ }^{22}$.

El concepto de sujeto que maneja el (post)operaismo también tiene una fuerte influencia foucaultiana. Fue Foucault quien liberó el tema de la subjetividad de

20 Cocco, G., Altamira, C., Horowicz, A., Negri, A., Diálogo sobre la globalización, la multitud y la experiencia argentina. Buenos Aires: Paidós, 2003, 260.

21 Berardi, F. (Bifo). Precarious Rhapsody. Semiocapitalism and the pathologies of the post-alpha generation. London: Minor Compositions, 2009, 59.

22 López Petit, S., La movilización global. Breve tratado para atacar la realidad. Madrid: Traficantes de Sueños, 2009, 16. 
su legado hegeliano, del subjetivismo idealista e historicista. Para Foucault, el sujeto no pre-existe ni a la historia ni al proceso social; como tampoco precede a las formaciones de poder o la subjetivación política que funda la autonomía: «la subjetividad ya no es identificada en los modos monolíticos propios de la ideología, de la política y de la pertenencia social, sino mediante toda una microfísica de las necesidades, del imaginario y del deseo. Esta noción de microfísica del deseo también fue introducida por Foucault, y posteriormente fue desarrollada por Deleuze y Guattari en el Anti-Edipo» ${ }^{23}$.

En el segundo apartado de este artículo introdujimos el concepto «composición de clase» como derivado de la «revolución copernicana» de Mario Tronti. En tono a la «composición de clase» tiene lugar un punto de convergencia fuerte entre el (post)operaismo italiano y el post-estructuralismo francés. Si la corriente francesa tiene una visión de la sociedad como realidad fluida y molecular, el concepto «composición de clase» contribuyó, justamente, a imaginar esa dinámica social como un proceso fluido. Detengámonos sobre este punto.

En Mil Mesetas, Deleuze y Guattari sostienen que nuestra vida está atravesada por tres tipos de líneas: las de segmentariedad molar, las de segmentariedad molecular y las líneas de fuga ${ }^{24}$. La línea molar marca, delimita y planifica un territorio estático, permite dividir y cartografiar a partir de una apropiación estructurante del flujo de la vida. Estas líneas son las que determinan la identidad y la transforman en una categoría histórica. El segundo tipo de línea, de segmentariedad molecular, se caracteriza, en cambio, por ser no estática sino flexible y fluyente, las relaciones que establece son menos localizables que las líneas de segmentariedad molar, y están en permanente cambio. Por el contrario, en el tercer tipo de línea ya no podemos hablar propiamente de segmentos, sino de líneas de fuga. Este tipo de línea no territorializa como las líneas molares, ni desterritorializa para después territorializar como lo hacen las moleculares. Aquí se trata de la desterritorialización absoluta, la pérdida de referencia total, la ruptura de la identidad y la apertura al puro devenir.

En relación a esta división tripartita de líneas que atraviesan nuestras vidas, el concepto de «cuerpos sin órganos» acuñado por Deleuze y Guattari pretendía romper con la idea del cuerpo como receptáculo de una conciencia y de una identidad, territorializado en una línea de segmentariedad molar. "Cuerpo sin órganos», entendemos, remite al método descriptivo "composicionista», "siendo el "cuerpo sin órganos" "el campo sobre el cual se produce continuamente el atravesamiento recíproco, el continuo fluir molecular. El método "composicionista" sitúa en la dimensión molecular los procesos de formación transversal de esos agregados inestables, mudables y provisionales, o sea, la subjetividad ${ }^{25}$. Estas posibilidades teóricas son precisamente las que explora también Negri cuando vincula el concepto marxiano de general intellect con el de "cuerpos sin órganos».

23 Berardi, F. (Bifo), Alice è il diavolo: Storia di una radio sovversiva. Shake Edizioni Underground, 2002, 43.

${ }^{24}$ Deleuze, G., Mil mesetas: capitalismo y esquizofrenia, José Vázquez Pérez, tr., Valencia: Pre-Textos, 1994.

25 Berardi, F. (Bifo), "A la memoria de Jean Baudrillard". Archipiélago. Cuadernos de crítica de la cultura. núm. 75, pp. 7-10, 2007. 
Cada instante de la subjetivación es «cuerpo sin órganos», esto es, potencialidad inexpresada, devenir.

Siguiendo con la división de las líneas antes expuesta, podemos señalar otro aspecto relevante que guarda relación teórica con aquello que señalábamos también en ese primer apartado, acerca de la labor desempeñada por los primeros teóricos operaistas, miembros de la revista Quaderni Rossi, consistente en cartografiar en las fábricas la emergencia de las nuevas figuras obreras y especialmente sus aspectos subjetivos más subversivos, lo que se conoció como «rechazo del trabajo». El proyecto operaista de «rechazo del trabajo» encuentra un corpus teórico similar en la concepción de las «líneas de fuga» desarrollada por Deleuze y Guattari. Desde la perspectiva operaista del «rechazo del trabajo», no es que los obreros sigan una línea de fuga, vayan tras ella, sino que ellos mismos, en su actividad — rechazando el trabajo- la constituyen. Dicho en términos deleuzianos, es la identidad «que se hace siendo»; y dicho en términos operaistas, es el sujeto que se constituye en la lucha, la clase se «compone».

Toni Negri es uno de los autores que más se dejó afectar por el encuentro con los teóricos post-estructuralistas. Decimos «afectar» porque de cuantos entraron en contacto con el pensamiento francés, Negri era, y es, el más marxista de todos. Cuando se exilia a Francia, comienza a trabajar y ejercer como docente en el Collège International de Philosophie de la Universidad París VIII (Sant Denis), donde entra en contacto con Foucault, Deleuze y Guattari. Ya desde los años setenta Negri venía enfrentándose con el corpus teórico tradicional de los intelectuales del PCI:

Enjuagar la ropa íntima en el Sena, se trataba de confrontar el operaismo italiano y el pensamiento post-estructuralista francés, y de procurar así un cortocircuito entre Foucault y Deleuze por un lado, y las luchas obreras que se habían desarrollado en Italia —y no solo el pensamiento que habían producido—, por el otro. [...] Pero si esta situación representaba una hipótesis, el problema consistía en «encarnar» la filosofía francesa en la práctica italiana y, por consiguiente, sondear en la ontología teórica de la liberación en busca del contenido destructivo de la práctica ${ }^{26}$.

A partir del pensamiento de los autores franceses, Negri vislumbró la posibilidad de escapar de la herencia economicista de la izquierda occidental. En octubre de 1984, Negri le escribe una carta a Guattari en la que le dice: «totalidad es siempre la del enemigo». A partir del segundo exilio francés, Negri incorpora con fuerza el lenguaje post-estructuralista, e intenta traducir las ideas (post)operaistas y del autonomismo italiano a la luz del lenguaje filosófico francés:

Hemos mantenido juntos a Foucault y a Marx. Mejor dicho, en lo que a mí concierne, puedo decir que me he «doctorado» en el Sena, es decir, he mezclado mi marxismo operaista con las perspectivas del post-estructuralismo francés. Ya había comenzado a hacerlo en los años de prisión (1979-1983), trabajando sobre Spinoza, un perfecto terreno de encuentro ontológico para tal operación. Luego, con Hardt en París, profundizamos en este análisis y nos sumergimos en aquella

26 Negri, A., Del retorno. Abecedario biopolitico, Inés Bértolo, tr., Barcelona: Debate, 2004, 18. 
«aura» común que, aunque desconocida, unía desde la década de 1960 a operais$m o$ con el post-estructuralismo ${ }^{27}$.

De entre los pensadores post-estructuralistas franceses, Toni Negri encuentra en Deleuze su interlocutor privilegiado: «no hay duda de que Deleuze y Guattari constituyen un referente decisivo en mi passe-partout de posmodernidad ${ }^{28}$. De Negri -y al hilo del comentario anterior de Michael Hardt acerca del papel de Francia en el siglo XX como productora de metafísica, e Italia como lugar de recepción de la teoría para un devenir con un marcado carácter político- podemos decir que es el traductor político de Deleuze. Al respecto, decía Hardt que a resultas del encuentro muchos conceptos aparecen transformados, «así, recibimos una versión de la filosofía post-estructuralista claramente comprometida políticamente» ${ }^{29}$.

Por un lado, Negri intenta ir más allá de Marx; y, por otro, recoge la aportación deleuziana, traduciendo las implicaciones políticas de este planteamiento. El encuentro de Negri con Deleuze está mediado por Spinoza. La relación teórica de Negri con Deleuze comienza precisamente con la obra de este último sobre Spinoza, dado que el filósofo italiano no había leído ninguna de sus obras anteriores. En Negri, el paso de Hegel a Spinoza, la afirmación de la diferencia, supone el paso del sujeto antagónico al sujeto constituyente; del sujeto que se reapropia al sujeto que despliega su potencia. El esfuerzo de Negri se ha concentrado en conciliar el materialismo histórico, es decir, una determinada lectura no dialéctica de Marx con el pensamiento de la multiplicidad y la diferencia.

El inmanentismo de la ontología materialista de Spinoza es la respuesta a la visión hegeliana de la historia como el despliegue de las fuerzas trascendentales. El proyecto negriano propone la elaboración de una genealogía materialista de las potencias constituyentes capaz de comprender las formas subjetivas que se producen en el antagonismo contra los poderes constituidos: «todo esto se inserta en la gran tradición materialista que va de Maquiavelo a Spinoza y a Marx y que solo nos dice una cosa: el deseo de liberación tiene una lógica ontológica irreductible. La inmanencia es este reino de posibilidades. Un telos no clásico sino ilustrado, no renacentista sino barroco, no moderno sino posmoderno» ${ }^{30}$.

En este sentido, Negri realiza una lectura del marxismo como pensamiento inscrito en una dialéctica no negativa, una dialéctica en la que no hay resolución - contrario a la Aufhebung hegeliana-, no hay una superación de la contradicción. Es una lectura del marxismo como pensamiento sobre la ruptura de los términos que son puestos en relación; como pensamiento de la diferencia respecto de todo pensamiento de la identidad. Cuando la dialéctica es conceptualizada desde el antagonismo — entendido éste como lógica de la separación—, entonces la dialéctica

27 Negri, A., Los libros de la autonomía, Marta Malo, Raúl Sánchez Cedillo, tr., Madrid: Akal, 2004, 22-23.

28 Cesarino. Op. cit., p. 147.

29 Por ejemplo, el mismo concepto de «multitud» de Hardt y Negri se inicia con el paso del fordismo al postfordismo. Comenzaron sus investigaciones con las determinaciones materiales y no formales. Esta manera que tienen de entender la constitución de las singularidades es una concepción propiamente materialista.

30 Negri, A., Fábricas del sujeto/ontología de la subversión, Marta Malo, Raúl Sánchez Cedillo, tr., Madrid: Akal, 2006, 83. 
es lucha entre contrarios, afirmación/negación. Si, por el contrario, la dialéctica fuese entendida en forma hegeliana, esto es, como síntesis, entonces ya no se presentaría como enfrentamiento, sino como negación de la negación, o sea, como superación de la relación antagonista.

Lo que más le sorprendió de Deleuze fue su capacidad para dar conceptualmente forma a ese conjunto de potencias. Dicho en otros términos: le sorprendió su capacidad para deshacer el horizonte estructural. En Imperio ${ }^{31}$, Hardt y Negri reconocen explícitamente su deuda con la obra de Deleuze y Guattari Mil Mesetas. El trabajo de los filósofos franceses se le presenta a Negri y Hardt como desmitificador del estructuralismo y de todas las concepciones filosóficas, sociológicas y políticas que hacen de la fijación del marco epistemológico un punto de referencia ineludible:

Hasta aquel momento, aun dentro de la izquierda operaista, las definiciones de fuerza, de tendencia y de lucha se expresaban solo en función de una prefiguración general del sistema y dentro de ella. La estructura se hallaba siempre prefigurada. La acción de clase y, lo que era aún más importante para nosotros, las acciones de grupo y fuerzas sociales específicas emergentes, se entendían siempre dentro de una teleología necesaria y estructural [...] Pues bien, durante ese período pude decir que tuve que abandonar mi pensamiento, reescribirlo en francés. Mi encuentro con Deleuze me permitió superar esas limitaciones y supuso un cambio radical en mi investigación ${ }^{32}$.

En lo que a la relación de Negri con Foucault se refiere, podemos afirmar que estuvo marcada por cierta ambivalencia. De un lado, Negri defendió la metodología foucaultiana como esencial para la desmitificación de las instituciones jurídicopolíticas de la modernidad y para el análisis de la fenomenología del poder; pero, por otro, llegó a la conclusión de que en Foucault, en el final de su arqueología, no pudo aparecer un efectivo proceso de poder ${ }^{33}$. Desde la perspectiva negriana, la principal limitación del proyecto foucaultiano radica en que el proyecto arqueológico siempre fue movido desde arriba hacia abajo, mientras que la preocupación de Negri es pensar la oposición desde el movimiento de abajo. Escribe Negri: «escuché sus conferencias un par de veces en el Collège de France, y sus argumentos eran casi los de un historiador. Foucault siempre me dejaba profundamente insatisfecho» ${ }^{34}$. Negri entiende que Foucault era perfectamente consciente de estas limitaciones. Y de ahí el giro que toman las investigaciones del filósofo francés a mediados de los años setenta, según Negri. Será en la obra de Deleuze Diferencia y Repetición, sostiene Negri, donde por primera vez se confrontan y resuelven los problemas que dificultaban el proyecto de Foucault. Este último reconoció que Deleuze había encontrado las soluciones conceptuales que él mismo había estado buscando.

El concepto de «disciplina» también es objeto de discusión entre Negri y Foucault ${ }^{35}$. Aunque Negri y Foucault utilizan la noción de «disciplina» refiriéndose

31 Hardt, M., y Negri, A., Imperio, Alcira Bixio, tr., Barcelona: Debate, 2000.

32 Cesarino. Op. cit., p. 153.

33 Negri, A., Macchina tempo: rompicapi, liberazione, costituzione. Milàn: Feltrinelli, 1982.

34 Cesarino. Op. cit., p. 152.

35 Hardt, M., y Negri, A., Multitud. Guerra y democracia en la era del Imperio, Juan Antonio Bravo, tr., Barcelona: Debate, 2004. 
a las mismas prácticas, Negri le otorga al concepto un enfoque diferente. Para Foucault, la disciplina es desplegada mediante arquitecturas institucionales. El poder de la disciplina no se ubica en un lugar central, sino de forma capilar, siendo las subjetividades producidas mediante la internalización de la disciplina. Estas consideraciones foucaultianas son totalmente válidas para Negri. Sin embargo, el enfoque principal cambia, pues para el filósofo italiano se trata de cómo las prácticas e interrelaciones del disciplinamiento que se originan en el régimen fabril llegan a investir a todo el terreno social como mecanismo tanto de producción como de gobierno, esto es, como un régimen de producción social. Y, por extensión, cómo opera, desde este enfoque, lo inmaterial y lo comunicacional en el postfordismo.

De la obra de Foucault, Negri también ha prestado especial atención a los conceptos de «biopoder» y «biopolítica». Sin embargo, toma esta lectura en una dirección diferente, pues el concepto de biopolítica, a su juicio, necesita en última instancia encarar y abordar la cuestión del trabajo. La necesidad de abordar los conceptos desde la cuestión del trabajo está siempre presente en la obra de Negri, es una constante que nace de su definición como marxista, y, como tal, de la idea siempre vigente de que el mundo se construye a partir del trabajo vivo.

En este sentido, entiende su definición de la biopolítica ${ }^{36}$ como una ampliación de la investigación que Foucault había emprendido: en lugar de hacer caso omiso o dejar de lado la elaboración que Foucault hizo de la biopolítica en el contexto del ejercicio de la sexualidad, adoptó esa elaboración y la amplió a fin de dar cuenta de la construcción general del cuerpo en los ámbitos indistinguibles de la producción y la reproducción, es decir, en el ámbito del trabajo inmaterial. Esa ampliación de la investigación le permitió también clarificar algo que en Foucault había quedado, a juicio de Negri, relativamente indefinido: la relación entre biopolítica y biopoder.

Si permanecemos demasiado atados a un análisis filológico de los textos de Foucault, nos advierte Negri, podríamos pasar por alto la cuestión central: sus análisis del biopoder apuntan no solo a una descripción empírica de cómo funciona el poder para y a través de los sujetos, sino también al potencial de producción de subjetividades alternativas, indicando de tal suerte una distinción en la afirmación de Foucault según la cual la libertad y la resistencia son precondiciones necesarias para el ejercicio del poder.

Para Negri, en tanto la vida se ha vuelto enteramente productiva, interpreta la biopolítica no como un flujo paralizante sobre el conjunto de la sociedad, sino como la apertura de nuevas posibilidades de combinar creación y resistencia. Así, identifica el biopoder con la nueva figura de la soberanía y del mando sobre el trabajo. El biopoder es el poder sobre la vida, se configura sobre la reproducción del individuo y sobre la potencia biopolítica de los cuerpos. La biopolítica, por el

36 Negri, A., Commonwealth. El proyecto de una revolución del común, Raúl Sánchez Cedillo, tr., Madrid: Akal, 2011. Las principales corrientes de la interpretación de Foucault no comprenden adecuadamente la naturaleza dual de la biopolítica. Roberto Esposito analiza el terreno de la biopolítica principalmente desde el punto de vista de la gestión normativa de las poblaciones; y Agamben acepta que la biopolítica es un terreno ambiguo y de conflicto, pero concibe que la resistencia actúa solo en su límite más extremo, en los márgenes de una forma totalitaria de poder, al borde de la imposibilidad. 
contrario, la identifica con las potencias productivas de la vida: la producción de afectos, de lenguajes a través de la cooperación social, la interacción de cuerpos y deseos.

También afirma Negri que la biopolítica es «la creación de nuevas subjetividades que se presentan a la vez como resistencia y como desubjetivación» ${ }^{37}$. Es el terreno sobre el que la fuerza de trabajo ejercita a la vez su capacidad de producción y de resistencia. El campo de inmanencia es propuesto como el terreno biopolítico creativo. Es la expresión del deseo vital de los sujetos que se enfrenta con el biopoder. Decir que la vida resiste significa afirmar su potencia, es decir, su capacidad de creación, de invención, de producción y de subjetivación. Es lo que Negri llama «biopolítico»: la resistencia de la vida al poder, dentro de un mismo poder que ha investido la vida.

Si bien Negri reconoce su deuda con Mil Mesetas, y en relación al poder entiende que siempre resta potencia a la vida, esta vida no la concibe como algo personal o como un flujo - razón por la cual es en gran medida antibergsoniano. Su concepción de la vida no es vitalista. La concibe, más bien, como multitud de singularidades, que se juntan o se separan, y, al hacerlo, constituyen, producen juntas el momento de la constitución. Una multitud que se halla continuamente sometida a la sustracción de poder.

Con todo, en el planteamiento de Negri siempre permanecen diferencias importantes y sustanciales que separan sus posiciones de las de los filósofos franceses. En Marx más allá de Marx ${ }^{38}$, Negri señalaba las limitaciones de la corriente post-estructuralista que, en última instancia, radicaban en el hecho de no identificar un poder constituyente. En efecto, si para Deleuze el sujeto es siempre un residuo dejado por el deseo, una forma de dominio, para Negri el sujeto es el lugar de la identidad entre la fuerza productiva del ser y su constitución misma. Deleuze y Negri parten de una misma raíz spinoziana, pero adquieren dos enfoques distintos: para Deleuze, la ontología como experimentación liberadora; para Negri, la ontología como fenomenología de la praxis constitutiva del sujeto colectivo, es decir, «lo social» debe ser pensado como un sujeto constituyente.

Si Toni Negri encuentra en Deleuze su interlocutor privilegiado, Franco Berardi, más conocido por su pseudónimo Bifo, lo encuentra en Félix Guattari. Los análisis del poder contemporáneo que articula Bifo constituyen una clara continuación de los análisis post-estructuralistas del poder. Fue fundador de algunos de los proyectos comunicativos más importantes del movimiento italiano del 77, como la revista A/traverso o Radico Alice, una de las primeras y emblemáticas experiencias de radios libres europeas. Clausurada la radio por la policía, y arrestado Bifo en la operación judicial contra Autonomia Operaia, es liberado al poco, pero el trágico desenlace de los Anni di piombo ["Años de plomo»] fuerzan su exilio a París. Allí frecuenta a Guattari y Foucault. Durante los '80 vivió en Italia y Estados Unidos, donde colaboró con las revistas Semiotexte y Musica 80. En 1991 regresa a Bolonia y actualmente enseña historia social de los medios en la Academia di Belli Arti di Brera de Milán.

37 HardT, Negri, Ibid., 77.

38 Negri, A., Marx oltre Marx: quaderno di lavoro sui Grundrisse. Milano, Feltrinelli, 1979. 
En su exilio en París tuvo varios encuentros con Guattari, y también con Foucault: «me encontré con Félix personalmente recién en junio de 1977. En aquel año, en Bolonia tenía lugar una insurrección bizarra, que se inspiraba más en el dadaísmo y en el Anti-Edipo que en los manuales de la política revolucionaria ${ }^{39}$. El recorrido que Bifo hace del pensamiento de Guattari está articulado desde el interior de las elaboraciones teóricas y de la práctica político-existencial de la generación del 68 y el 77. Bifo, que razona en términos de autoorganización molecular del trabajo frente al capital-flujo, entiende que para ello es necesario acudir a los conceptos del «esquizoanálisis», en tanto que Deleuze y Guattari analizan el capitalismo contemporáneo como flujo semiótico y colocan sobre este plano la tarea de la crítica. En su libro Félix. Narración del encuentro con el pensamiento de Guattari. Cartografía visionaria del tiempo que viene, Bifo trata de seguir el desarrollo de la última década del siglo considerando al pensamiento rizomático como un mapa, procurando ver las huellas de lo real en continuidad con las líneas que el mapa contiene. En Bifo es notable el influjo de la tradición «cartográfica». Señala Diego Sztulwark en el prólogo a la edición Argentina del libro La sublevación, publicado por la editorial Hekt Libros:

Se personifica sobre todo en la figura de Félix Guattari. Bifo reinventa de forma original las prácticas cartográficas. Cartografía entendida como movimiento de la subjetividad que capta las mutaciones sobre un plano de inmanencia. Cartografías existenciales, afectivas y psíquicas del postfordismo. Cartografías expresivas, lingüísticas del semiocapitalismo. Cartografías de procesos maquínicos, técnicos, en torno a internet, las nuevas tecnologías y los procesos de trabajo.

Los análisis de Bifo están atravesados por un mismo interés: el análisis de los procesos de subjetivación. Lo primero que observa es que las categorías que se derivan de la economía política son insuficientes para el análisis de esos procesos de subjetivación, pues están atravesados por campos bastantes más complejos. De ahí que Bifo dibuje un campo disciplinar que es un encuentro entre la economía, la semiología y la psicoquímica; describe las mutaciones perceptuales y epistemológicas generadas por las condiciones socio-técnicas de la vida contemporánea bajo el capitalismo digital; transita del campo de la filosofía a la política y al psicoanálisis, de la biotecnología al ciberpensamiento, del esquizoanálisis a la comunicación; y revisita los nombres propios de la filosofía, Bergson, Nietzsche, Spinoza, Guattari y Deleuze.

Y, más en concreto, su investigación se desarrolla alrededor de un problema: las relaciones entre procesos sociales y la mutación tecnológica en curso, analizando sus efectos sobre las subjetividades y los imaginarios sociales. Es un teórico del semiocapitalismo, esto es, del modo de producción en el cual la acumulación de capital se hace esencialmente por medio de una producción y una acumulación de signos. También analiza las mutaciones perceptuales y epistemológicas generales por las condiciones socio-técnicas de la vida contemporánea bajo el hipercapitalismo digital. Es también un estudioso de las patologías del capitalismo semiótico.

39 Berardi, F. (Bifo), The soul at Work. From Alienation to Autonomy. Los Ángeles: Semiotext, 2009, 91. 
Otro de los teóricos (post)operaistas que se ha servido de los análisis postestructuralistas ha sido Yann Moulier-Boutang, quien, en su vasta obra De la esclavitud al trabajo asalariado. Economía histórica del trabajo asalariado embridado, en torno a la acumulación primitiva de la clase obrera y del trabajo asalariado en general $^{40}$, se sirve tanto del marco teórico del operaismo, como de una filosofía de la relación y del movimiento diferencial, presente en la obra de Deleuze y Guattari. En este sentido, la investigación de Moulier-Boutang es deudora de la Historia de la locura de Foucault; de la imagen-movimiento deleuziana; y de la potencia de la multitud en la fuga de Deleuze y Guattari.

Para Maurizio Lazzarato, Foucault, Deleuze y Guattari son también una importante fuente de inspiración, particularmente en la utilización de la diferencia y la repetición; los conceptos de mayoría y minoría, multiplicidad, acontecimiento, expresión, virtual, molar y molecular o biopolítica y biopoder; y la reflexión sobre las dinámicas creativas, que oponen regímenes de signos y de expresión al agenciamiento maquínico de los cuerpos. También recurre a la obra Mijail Bajtin, lingüista reivindicado por Deleuze, para explicar el alcance de la noción de acontecimiento en la política contemporánea.

Lazzarato elabora una fuerte crítica a la ontología de raíz hegeliana y apuesta por una ontología pluralista partiendo de la filosofía de la diferencia. Su diálogo con los otros autores (post)operaistas es permanente, con los que además comparte una larga trayectoria intelectual y política, pero discrepa —fundamentalmente con Negri y Virno- del proyecto de reactualización del marxismo. Sus críticas siempre permanecen en el interior de la corriente, señalando los posicionamientos filosóficos que no logran liberarse de la dialéctica amo/esclavo y su sometimiento a la lógica de la totalidad; si bien por momentos Lazzarato fideliza con el proyecto deleuziano sin necesidad de diálogo con el (post)operaismo.

Así, el acercamiento de Lazzarato a la obra de Marx no es a partir de la relación capital/trabajo, entendida como origen y fuente del mundo y de las relaciones de poder, sino a partir de todos los dispositivos, siendo el trabajo un dispositivo más entre otro. Para captar la dinámica del capitalismo postfordista no se refiere a las fuerzas «inmensas, exteriores y superiores» de la dialéctica capital/trabajo, sino a las fuerzas «multiplicadas, infinitesimales e internas». Lazzarato inscribe su metodología en la filosofía de la diferencia, a través de la cual moviliza y amplía el marco del marxismo. Piensa el conflicto no a partir de la contradicción dialéctica, de un dualismo de clases o de una división amigo/enemigo, sino elaborando una política que toma la multiplicidad como materia prima. A partir de la obra de Deleuze establece la ruptura entre el marxismo y el pluralismo, es decir, entre una ontología de la producción y una ontología de la creación.

Concluyendo, a pesar de que las contingencias biográficas, marcadas por la fuerte represión sobre muchos de los miembros del operaismo italiano, que claramente están a la base del encuentro entre ambas corrientes de pensamiento, consideramos que el encuentro no ha sido una mera casualidad motivada por acontecimientos políticos o biográficos. Antes bien, lo que abre la verdadera

40 Moulier-Boutang, Y., De la esclavitud al trabajo asalariado. Economía histórica del trabajo asalariado embridado. Madrid: Akal, 2006. 
posibilidad de encuentro entre ambas corrientes son los lazos teóricos profundos que preexistían a la contingencia del encuentro. En este sentido, el cruce entre el (post)operaismo italiano y el post-estructuralismo francés es tanto un proyecto para reunir ambos pensamientos, como un proceso de revelamiento de resonancias. Desde esta perspectiva, podríamos hablar de una relación simbiótica entre la experiencia italiana y francesa. Si bien es cierto que la recepción solo se ha dado, fundamentalmente, en un sentido: del pensamiento francés al italiano, un único flujo.

\section{BiBLIOGRAFÍA}

Berardi, F. (Bifo) (2004). Il sapiente, il mercante, il guerriero. Dal rifiuto del lavoro all'emergere del cognitariato. Roma: DeriveApprodi, 231.

- (2007). «A la memoria de Jean Baudrillard». Archipiélago. Cuadernos de crítica de la cultura. núm. 75, pp. 7-10.

- (2002). Alice è il diavolo: Storia di una radio sovversiva. Shake Edizioni Underground.

- (2007). Generación post-alfa. Patologías e imaginarios en el semiocapitalismo, Patricia Amigot, Manuel Aguilar, Diego Picotto, tr. Buenos Aires: Tinta Limón.

- (2013). La sublevación. Barcelona: Artefakte, [2011].

- (2009). Precarious Rhapsody. Semiocapitalism and the pathologies of the post-alpha generation. London: Minor Compositions.

- (2009). The soul at Work. From Alienation to Autonomy. Los Ángeles: Semiotext.

Casarino, C., y Negri, A. (2001). Elogio de lo común. Barcelona: Paidós.

Cocco, G., Altamira, C., Horowicz, A., y Negri, A. (2003). Diálogo sobre la globalización, la multitud y la experiencia argentina. Buenos Aires: Paidós3.

Deleuze, G. (1994). Mil mesetas: capitalismo y esquizofrenia, José Vázquez Pérez, tr., Valencia: Pre-Textos.

Hardt, M., y Negri, A. (2000). Imperio, Alcira Bixio, tr., Barcelona: Debate.

- (2004). Multitud. Guerra y democracia en la era del Imperio, Juan Antonio Bravo, tr., Barcelona: Debate.

Hardt, M., y Virno, P. (eds.) (1996). Radical Thought in Italy: A Potential Politics. Minneapolis: University of Minnesota Press.

López Petit, S. (2009). «La precariedad como forma de humillación. Algunas reflexiones muy provisionales sobre la precariedad». En Delgado, M. (ed.). La humillación. Técnicas y discursos para la exclusión social. Barcelona: Bellaterra9.

- (2009). La movilización global. Breve tratado para atacar la realidad. Madrid: Traficantes de Sueños.

Marx, K. (2007). Elementos fundamentales para la crítica de la economía política (Grundrisse). Madrid: Siglo XXI.

Moulier-Boutang, Y. (2006). De la esclavitud al trabajo asalariado. Economía histórica del trabajo asalariado embridado. Madrid: Akal.

Negri, A. (1993). «Entrevista de Gilles Deleuze con Toni Negri», Magazín Dominical, núm. $511,14-18$.

- (2011). Commonwealth. El proyecto de una revolución del común, Raúl Sánchez Cedillo, tr. Madrid: Akal.

- (1979). Dall'operaio massa all'operaio sociale: intervista sull'operaismo (a cura di Paolo Pozzi e Roberta Tommasini). Milano: Multhipla.

- (2004). Del retorno. Abecedario biopolítico, Inés Bértolo, tr. Barcelona: Debate. 
- (2006). Fábricas del sujeto/ontología de la subversión, Marta Malo, Raúl Sánchez Cedillo, tr. Madrid: Akal, 83.

- (2002). Job, la force de l'esclave. Paris: Bayard.

- (2000). Kairos, Alma, Venus, Mutitudo. Roma: Manifestolibri.

- (1993). La anlomalía salvaje. Ensayo sobre poder y potencia en Baruch Spinoza. Barcelona: Anthropos.

- (2004). Los libros de la autonomía, Marta Malo, Raúl Sánchez Cedillo, tr. Madrid: Akal.

- (1982). Macchina tempo: rompicapi, liberazione, costituzione. Milàn: Feltrinelli.

- (1979). Marx oltre Marx: quaderno di lavoro sui Grundrisse. Milano, Feltrinelli.

Pasquinelli, M. (2013). «La potenza di astrazione e il suo antagonismo. Sulle psicopatologie del capitalismo cognitivo», UniNomade 2.0, 28, marzo, 2013 [http://www.uninomade.org/ la-potenza-di-astrazione-e-il-suo-antagonismo/] [Consultado: 31 de marzo de 2013].

Revelli, M. (2002). Más allá del siglo XX. La política, las ideologías y las asechanzas del trabajo, María del Mar Portillo y Marco Barberi, tr. Barcelona: El Viejo Topo.

Sandro, M. (2011). «En la época de lo post». En Marazzi, C., Berardi, F. (Bifo), y Mezzadra, S. (2011). Balance conceptual del post-operaismo en Italia. Espai en Blanc: El impasse de lo político, núm. 9, pp. 293-297.

Tronti, M. (2001). Obreros y capital, Oscar Chávez Hernández, David Gámez Hernández, Carlos Prieto del Campo, tr. Madrid: Akal, [1996].

Universitat de Barcelona

Antonio Gómez Villar

Universitat Autónoma de Barcelona

antonio.gomez.villar@hotmail.com

[Artículo aprobado para publicación en diciembre de 2016] 